\title{
Idiopathic Granulomatous Mastitis Mimicking Breast Abscess
}

\author{
Mona Al Fares, $\mathrm{MD}^{1}$; Yasin Ahmed $\mathrm{MD}^{2}$; Jeffery Falk, $\mathrm{MD}^{3}$; Lawrence E. Briski, $\mathrm{MD}^{4}$; \\ Mamta Sharma, MD, Fellow ACP \\ ${ }^{1}$ St. John Hospital \& Medical Center, Detroit, Michigan \\ ${ }^{2}$ King Abdulaziz University Hospital, Jeddah, Saudi Arabia
}

\section{Introduction}

Idiopathic granulomatous mastitis is a rare chronic inflammatory breast condition that can mimic breast abscess and breast cancer. Granulomatous mastitis typically presents as a unilateral breast mass. We present a case of idiopathic granulomatous mastitis mimicking breast abscess.

\section{Case Report}

24-year-old African American female, gravida 1 para 1, presented with a 4-month history of recurrent right breast abscess. The patient had no significant past medical history. She was on intramuscular medroxyprogesterone acetate for contraception for last 3 years.

She was given oral Amoxicillin-clavulanate for 1 month without improvement. Ultrasound showed a $1.7 \times 3.4$ x 2.1 $\mathrm{cm}$ mass. She was referred to a breast surgeon 2 months later who incised and drained purulent material from the lesion; tissue gram stain and cultures remained negative. She was started on vancomycin for suspected methicillinresistantstaphylococcus aureus and discharged on trimethoprim-sulfamethoxazole and subsequently developed a rash to trimethoprim-sulfamethoxazole.

She improved after surgical drainage, then again developed swelling of her right breast and was re-admitted 1 month later.

On examination she was afebrile. Right breast mass was tender on palpation with superficial erythema without lymphadenopathy.

Wide surgical excision of $10 \times 9.5 \times 3 \mathrm{~cm}$ of right breast was performed which revealed minimal purulence and fat necrosis. Tissue cultures were negative including mycobacterium and fungal except one culture which grew rare corynebacterium species which was considered contaminant. Histopathology was consistent with granulomatous inflammation with fat necrosis consistent with idiopathic granulomatous mastitis (Figure 1-3).

The patient was discharged on 7th day of hospitalization with close follow-up. She was started on prednisone with excellent clinical response.

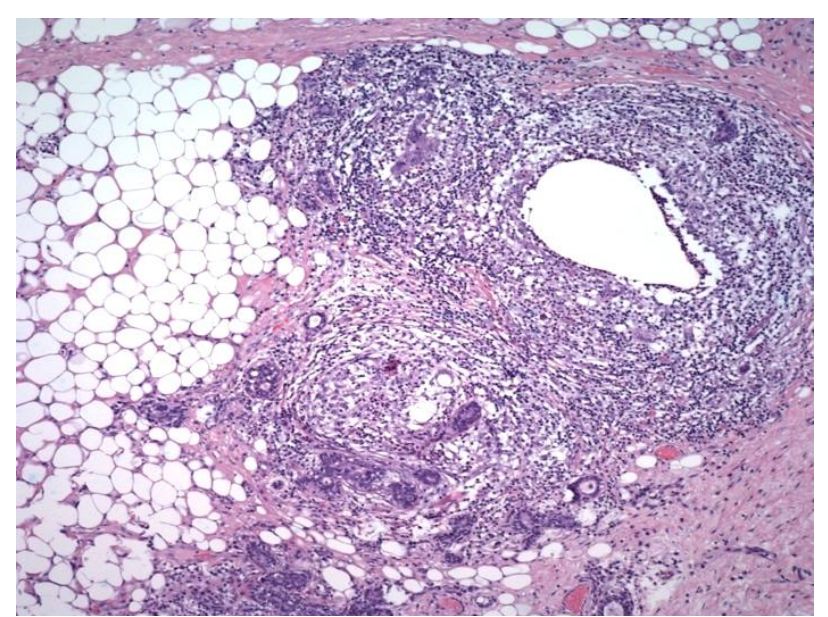

Figure 1: Fat Necrosis along with chronic inflammation and giant cell response

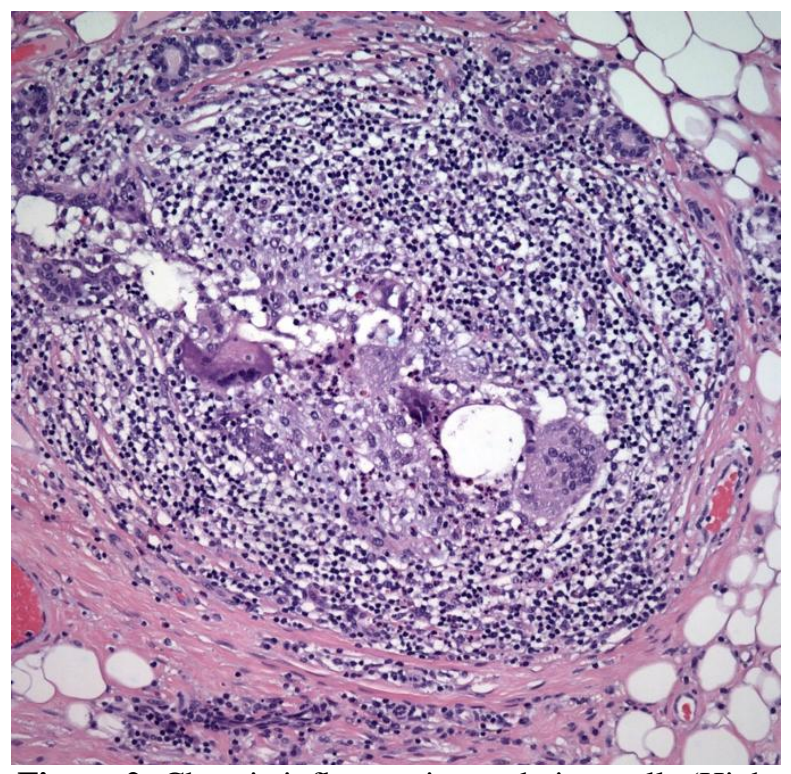

Figure 2: Chronic inflammation and giant cells (High power) 


\section{International Journal of Science and Research (IJSR) \\ ISSN (Online): 2319-7064}

Index Copernicus Value (2013): 6.14 | Impact Factor (2015): 6.391

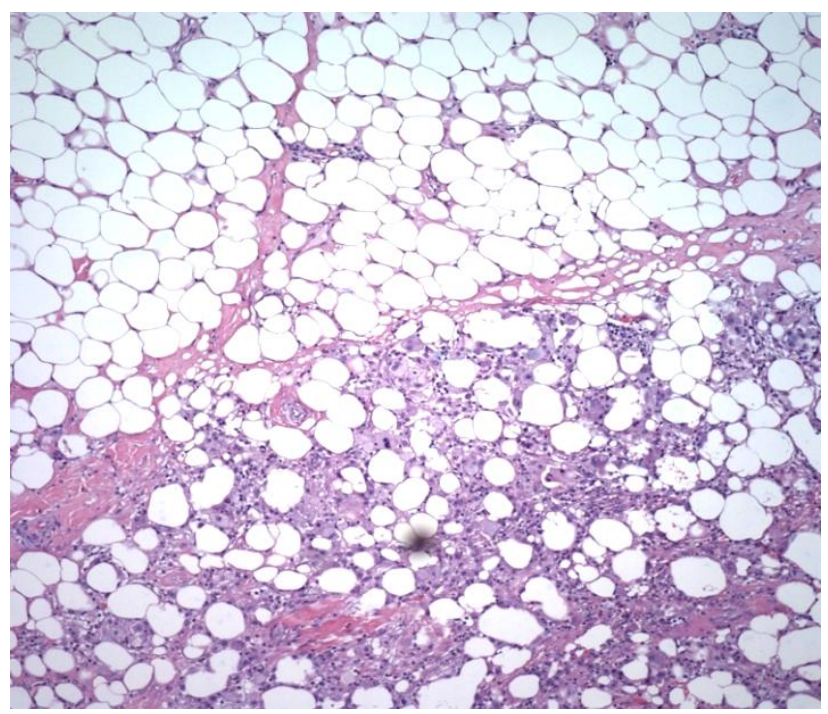

Figure 3: Fat Necrosis (upper left) with histiocytes and chronic inflammation (lower right)

\section{Discussion}

Idiopathic granulomatous mastitis is an idiopathic condition affecting women of childbearing age. Etiology proposed includes localized immune reaction to breast, oral contraceptives, pregnancy, breast feeding and trauma. Lesions are of variable size firm tender ill-defined usually unilateral.

Differential diagnosis includes bacterial mastitis, tubercular or fungal mastitis, foreign body granulomas, sarcoidosis and Wegener's granulomatosis.

Mammogram and ultrasound findings are nonspecific.

Definitive diagnosis is by histopathological examination which features non caseating granulomas with histiocytes, giant cells and negative microbiology.

Treatment modalities include close follow up, immunosuppression with corticosteroids with or without methotrexate and or surgical excision.

\section{Conclusions}

Idiopathic granulomatous mastitis can mimic breast abscess.Recognition of this entity should be considered in recurrent sterile breast abscess.Definitive diagnosis requires histopathological examination.Treatment include immunosuppression with or without surgical excision.

\section{References}

[1] Patel RA, Strickland P, Sankara IR, Pinkston G, Many W $\mathrm{Jr}$, Rodriguez M. Idiopathic granulomatous mastitis: case report and review of literature $\mathbf{J}$ Gen Intern Med 2010;270-3.

[2] Centers for Disease Control and Prevention (CDC). Idiopathic granulomatous mastitis in Hispanic women Indiana, 2006-2008. MMWR Morb Mortal Wkly Rep 2009; 58:1317-21.
[3] Marriott DA, Russell J, Grebosky J, Wallace AM, Joste $\mathrm{N}$, Royce ME Idiopathic granulomatous lobular mastitis masquerading as a breast abscess and breast carcinoma.

\section{Am J Clin Onco 2007; 30:564-5 \\ [4]}

